\title{
Preparation of New Polybenzothiazole-Polyimide Blends through Polymerization Blending of Polyamic Acids in Precursor Polyamide Solution for Polybenzothiazole
}

\author{
Tatsuya Hattori, ${ }^{\dagger}$ Kazuhiro Kagawa, Masa-aki KaKimoto, ${ }^{*}$ \\ and Yoshio IMaI* \\ Wako Research Center, Honda $R \& D$ Co., Ltd., \\ Chuo, Wako-shi, Saitama 351-01, Japan \\ * Department of Organic and Polymeric Materials, Tokyo Institute of Technology, \\ Meguro-ku, Tokyo 152, Japan
}

(Received September 30, 1994)

\begin{abstract}
A new method so called polymerization blending of polyamic acids was carried out in the solution of the precursor polyamide for rigid-rod polybenzothiazole (PBZT) as reinforcement, leading to the formation of PBZT-polyimide blend films. The morphology of the transparent films, obtained by the polymerization blending, casting, coagulation, and thermal treatment, was observed by scanning electron microscopy (SEM) in order to investigate the state of dispersion of the PBZT in the films. The SEM photographs showed that the PBZT was well dispersed at micro-level. Mechanical properties of the films were improved in modulus and tensile strength, which were corresponded well with the morphology of the films; furthermore, dynamic mechanical analysis was also performed to characterize the films consisted of respective polyimides as a matrix. The method of polymerization blending leads to an effective way to achieve the micro-composites consisted of the PBZT and the polyimides with ideal dispersion of the reinforcement and hence having excellent mechanical properties.

KEY WORDS Polymerization Blending / Blend Films / Micro-Composites / Polybenzothiazole / Polyimides / Precursor Polyamides / Mechanical Properties /
\end{abstract}

Aromatic polybenzothiazoles have been known as a class of rigid-rod heterocyclic polymers $^{1-3}$ and have been taken great interest because these polymers have potential for fabrication into high-strength and high-modulus fibers and films. ${ }^{4-8}$ Recently, we have developed a new series of soluble precursor aromatic polyamides (aramids) having protected thiol groups, which could be converted by thermal treatment to the corresponding polybenzothiazoles. ${ }^{9-12}$

In this connection, we have aimed to prepare high performance micro-composites consisted of polyimides as matrices and the polymer (PBZT) as reinforcement through the new precursor polyamide derived from 2,5-bis[[(methoxycarbonyl)ethyl] thio]-1,4-phenylenediamine and 2-chloroterephthaloyl chloride. In order to obtain the high performance composites with excellent mechanical properties, the reinforcing polymer should be dispersed in the matrix polymer as fine as possible; thus, the extreme concept of molecular composites, where the reinforcing polymer such as rigid-rod polybenzothiazole or aramid was finely dispersed in matrix polymers at molecular level, have been proposed and materialized as new types of composites. ${ }^{13-16}$

Since reinforcing polymers and flexible-coil

\footnotetext{
† To whom all correspondence should be addressed.
} 
polymers as matrix are generally incompatible in nature leading to ready phase separation, the above named polymerization blending or the in-situ direct polycondensation is a suitable method to achieve good compatibility and fine dispersion in the composites. ${ }^{17-21}$

We have developed here a new method of polymerization blending where polyamic acid was synthesized in the polymer solution consisted of an organic solvent and the precursor polyamide for the PBZT as reinforcement, followed by conversion of the precursor blend films to micro-composite films through thermal cyclization of both polyamic acid and precursor polyamide simultaneously. Thus the blending films were prepared without use of any strong acids, which are generally used as blending solvents in case of blending of rigidrod polymers and flexible matrix polymers due to insolubility of rigid-rod reinforcements in common organic solvents. ${ }^{14,15}$ Furthermore, we have adopted the method of wet-coagulation to remove the solvent from the blend solution instantly and freeze the state of fine dispersion of the polymers in solution, thereby avoiding phase separation during formation of the films.

The present paper deals with the preparation of the blend films consisted of the PBZT as rigid-rod reinforcement and two types of polyimides as flexible matrices through polymerization blending from the view point of morphology and mechanical properties. A comparison of the polymerization blending with a conventional solution blending is also described.

\section{EXPERIMENTAL}

\section{Materials}

Pyromellitic dianhydride (PMDA), 3, 3',4,4'benzophenonetetracarboxylic dianhydride (BTDA), 1,4-bis(4-aminophenoxy)benzene (APB), and 2-chloroterephthaloyl chloride were obtained commercially and used without further purification. $N$-Methyl-2-pyrrolidone
(NMP) was purified by vacuum distillation with calcium hydride.

\section{Monomer Synthesis}

2,5-Bis[[(methoxycarbonyl)ethyl]thio]-1,4phenylenediamine (METP) was prepared from 2,5-diamino-1,4-benzenedithiol dihydrochloride and methyl 3-bromopropionate according to the method reported previously. ${ }^{10}$ 2,6-Bis(4-aminophenyl)benzobisthiazole (DAPBT) was synthesized by the reaction of 2,5-diamino-1,4-benzenedithiol dihydrochloride with 4-aminobenzoic acid in polyphosphoric acid according to the method described in the literature. ${ }^{22}$

\section{Polymer Synthesis}

The precursor polyamide was synthesized by the following method. To a solution of $3.444 \mathrm{~g}$ $(10.0 \mathrm{mmol})$ of METP in $20 \mathrm{ml}$ of NMP was added $2.375 \mathrm{~g}(10.0 \mathrm{mmol})$ of 2-chloroterephthaloyl chloride in one portion at $0^{\circ} \mathrm{C}$ with stirring. After stirring at $20-25^{\circ} \mathrm{C}$ for $6 \mathrm{~h}$, the solution was poured into $500 \mathrm{ml}$ of methanol. The precipitated polymer was collected by filtration, washed repeatedly with methanol, and dried at $80^{\circ} \mathrm{C}$ under vacuum. The inherent viscosity of the polyamide was $1.60 \mathrm{dlg}^{-1}$, measured at a concentration of $0.5 \mathrm{~g} \mathrm{dl}^{-1}$ in NMP at $30^{\circ} \mathrm{C}$.

Matrix polyimides, [PI(PMDA/APB)] and [PI(BTDA/DAPBT)], were prepared via polyamic acids, [(PAA(PMDA/APB) $]$ and [(PAA(BTDA/DAPBT)], which were synthesized from combinations of PMDA and APB, and of BTDA and DAPBT, respectively, by a conventional solution polymerization in NMP.

\section{Blend Films by Polymerization Blending}

A typical example of the preparation of the polymerization-blended films is given below. To a solution of $1.615 \mathrm{~g}(4.314 \mathrm{mmol})$ of DAPBT in $5.0 \mathrm{ml}$ of the polyamide solution, which was prepared by dissolving $0.253 \mathrm{~g}$ of the precursor polyamide in $9.0 \mathrm{ml}$ of NMP, was added $1.390 \mathrm{~g}(4.314 \mathrm{mmol})$ of solid BTDA in 
one portion with stirring at $20^{\circ} \mathrm{C}$. The solution went into viscous gradually with time. The solution consisting of the polyamide and the polyamic acid was stirred for $15 \mathrm{~h}$ to give clear solution. A film was obtained by casting the solution onto a glass plate by using a blade, followed by dipping the glass plate into water in order to extract the solvent. A transparent film came up to the water surface in a few minutes. The film was dried at $80^{\circ} \mathrm{C}$ under vacuum, and then heated at 100, 200, and $330^{\circ} \mathrm{C}$ for $1 \mathrm{~h}$ each. The film thus obtained contained $5 \mathrm{wt} \%$ of the PBZT as calculated value, having a thickness of about $10-20 \mu \mathrm{m}$. The films containing 10,11 , and $15 \mathrm{wt} \%$ of the PBZT were also prepared by the same way.

\section{Blend Films by Solution Blending}

To a solution of $1.615 \mathrm{~g}(4.314 \mathrm{mmol})$ of DAPBT in $9.0 \mathrm{ml}$ of NMP was added $1.390 \mathrm{~g}$ $(4.314 \mathrm{mmol})$ of solid BTDA in one portion with stirring at $20^{\circ} \mathrm{C}$ and the solution went into viscous gradually with time. After stirring at $20-25^{\circ} \mathrm{C}$ for $15 \mathrm{~h}$, the solution was mixed with the solution of the precursor polyamide, which was previously prepared by dissolving $0.253 \mathrm{~g}$ of the polyamide in $5.0 \mathrm{ml}$ of NMP at $40^{\circ} \mathrm{C}$. The mixture of the polyamic acid and the polyamide in NMP was allowed to stand at $-15^{\circ} \mathrm{C}$ for 7 days with occasional stirring to give clear solution. A film was obtained from the mixture on a glass plate by casting with use of a blade, and the glass plate was dipped into water. After the film was taken off and dried at $80^{\circ} \mathrm{C}$ under vacuum, it was heated at 100 , 200 , and $330^{\circ} \mathrm{C}$ for $1 \mathrm{~h}$ each. The film contained $5 \mathrm{wt} \%$ of the PBZT as calculated value, furthermore, the film contained $10 \mathrm{wt} \%$ of the PBZT was also prepared by the same way.

\section{Characterization of Films}

Dispersion state of the PBZT in the matrix polyimides was observed by scanning electron microscopy (SEM) (JEOL, JSM-T330) of the residue for the films after selective decomposition and removal of the polyimides with hydrazine. Measurements of the tensile properties were conducted by using a ToyoBaldwin Tensilon at $20^{\circ} \mathrm{C}$ at a crosshead speed of $2 \mathrm{~mm} \mathrm{~min}^{-1}$. Dynamic mechanical analysis (DMA) was performed by using a Toyoseiki Rheolograph-Solid in the tensile mode at a frequency of $10 \mathrm{~Hz}$ and a heating rate of $3^{\circ} \mathrm{C} \min ^{-1}$ in air.

\section{RESULTS AND DISCUSSION}

\section{Preparation of Blend Films}

The chemical structure of the precursor polyamide, the PBZT as rigid-rod reinforcement, the polyamic acids, and the matrix polyimides are shown in eq $1-3$. Chlorine atom was introduced as bulky pendant group on the precursor polyamide backbone in order to make the polyamide soluble in NMP.

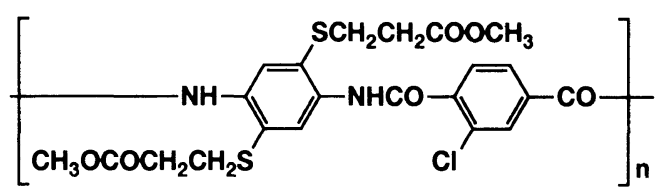

Precursor polyamide

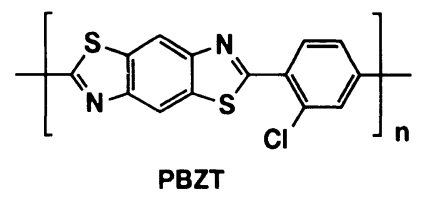


<smiles>CC(C)(C)Nc1ccc(Oc2ccc(Oc3ccc(Oc4ccc(NC(=O)c5cc(C(=O)O)c(C(=O)O)cc5C(=O)O)cc4)cc3)cc2)cc1</smiles><smiles>CC(C)(C)NCOc1ccc(C(=O)Oc2ccc(C(=O)O)c(C(=O)O)c2)cc1Nc1ccc(-c2nc3cc4sc(-c5ccc(C(C)(C)C)cc5)nc4cc3s2)cc1</smiles><smiles>CC(C)(C)c1ccc(-c2nc3cc4sc(-c5ccc(N6C(=O)c7ccc(OC(=O)c8ccc9c(c8)C(=O)N(C(C)(C)C)C9=O)cc7C6=O)cc5)nc4cc3s2)cc1</smiles>

PI(BTDA/DAPBT)

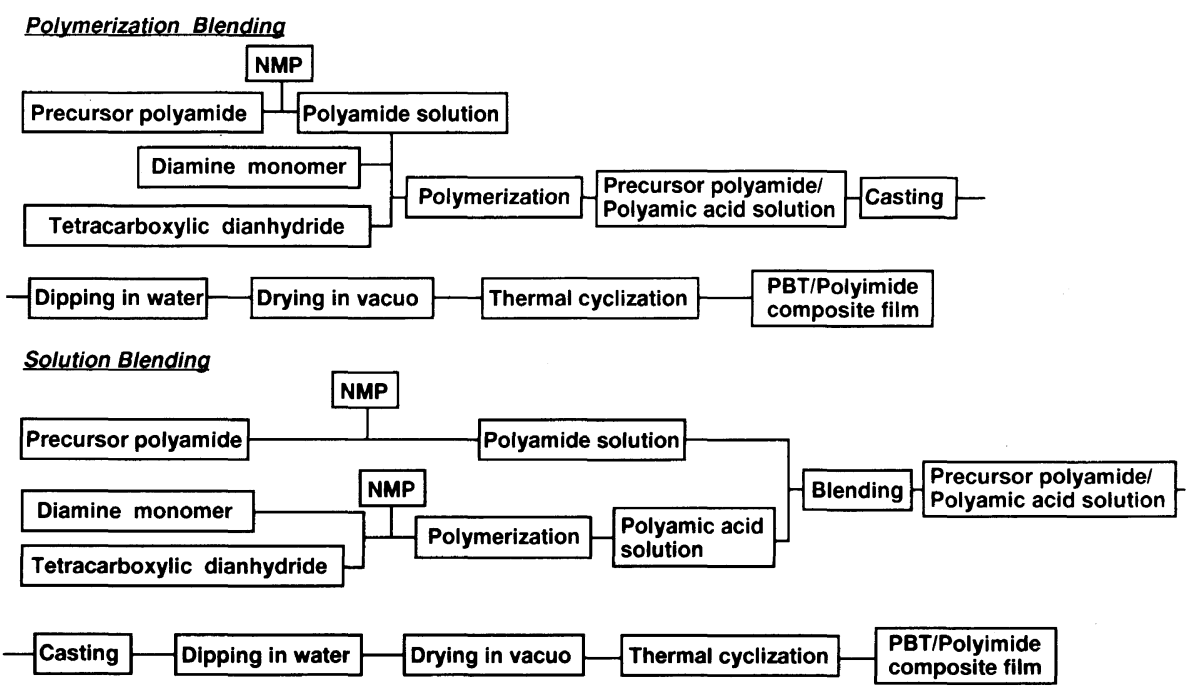

Figure 1. 1. Scheme for the preparation process of the PBZT-polyimides blend films.

The schemes for the preparation processes of blend films by means of the polymerization blending as well as the solution blending are shown in Figure 1. In the method of polymer- ization blending, the polyamic acids were synthesized in the polymer solutions containing the soluble precursor polyamide, giving clear and viscous solutions. The precursor 
films of the blends were obtained by the following steps: solvent-casting onto a glass plate, coagulation in a water bath, and drying in an oven under vacuum. The method of wet-coagulation adopted in this study was developed by Yamada and his co-workers to remove the solvent instantly and freeze as the state of the dispersion of the polymers in solutions. ${ }^{17}$ The films were heated successively at 100,200 , and $330^{\circ} \mathrm{C}$ for the cyclization reactions of both polymers, the precursor polyamide and the polyamic acid, under vacuum to give the transparent blend films.

As for the solution blending, the solution of the precursor polyamide dissolved in NMP was added to the polyamic acid solution synthesized by the solution polymerization method. The blending solution was obtained after allowing to stand for a week at $-15^{\circ} \mathrm{C}$ with occasional mixing. The transparent films of the blends were also obtained by the same manner of the polymerization blending.

\section{Morphology of Blend Films}

In order to study the micro-structure of the blend films by SEM, the polyimide components in each blend film consisted of the rigid-rod PBZT and the matrix polyimides through the polymerization blending or the solution blending were selectively decomposed with hydrazine to remain mostly the PBZT as reinforcement. After the matrices were decomposed, the residues which were rich with the PBZT should have reflected morphology of the reinforcement in the blends. Figure 2 shows that the residue from the blend of $5 \mathrm{wt} \%$ of the PBZT and PI(PMDA/APB) was welldispersed as fine particles with a diameter less than $0.5 \mu \mathrm{m}$, while the particles from the blend of $10 \mathrm{wt} \%$ of the PBZT were rather coarser than the former blend.

The residue from the blend of $10 \mathrm{wt} \%$ of the PBZT and PI(BTDA/DAPBT) by the polymerization blending was well-dispersed as fibrous structures with a diameter of about $0.2 \mu \mathrm{m}$ as shown in Figure 3(a); thus, the blend (a)

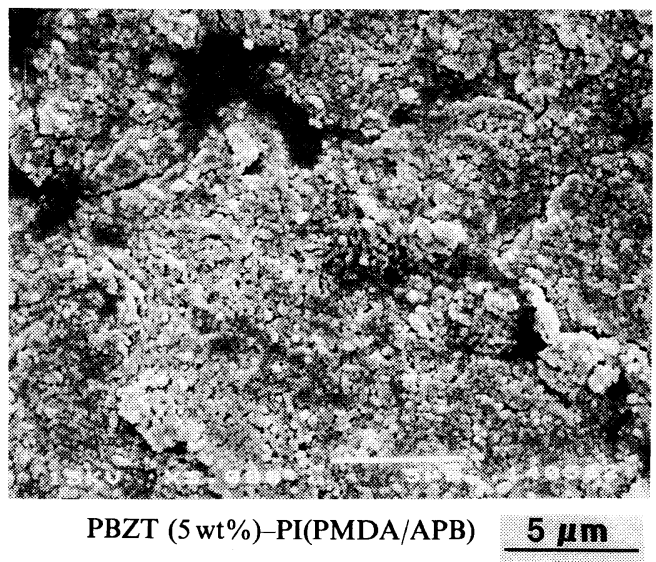

(b)

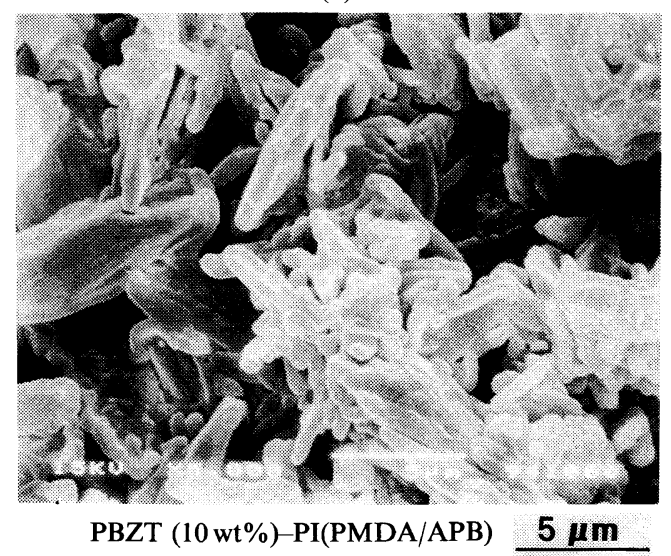

Figure 2. SEM photographs of the residue from the blends by the polymerization blending after treating with hydrazine: (a) the PBZT (5 wt\%)-PI(PMDA/APB) blend; (b) the PBZT (10wt\%)-PI(PMDA/APB) blend.

should be reinforced by the similar mechanism of short fiber reinforced composite. Figure 3(b) shows that the residue from the blend of $15 \mathrm{wt} \%$ of the PBZT was blocky and coarser particles with the size of about $1-3 \mu \mathrm{m}$. The photographs lead to the conclusion that the mechanism of reinforcement obviously changed between the blends of $10 \mathrm{wt} \%$ and $15 \mathrm{wt} \%$ of the PBZT resulting in quite different mechanical properties of the blend films.

The observation of the residue from the blend of $10 \mathrm{wt} \%$ of the PBZT and PI(BTDA/ DAPBT) by the solution blending method was 
(a)

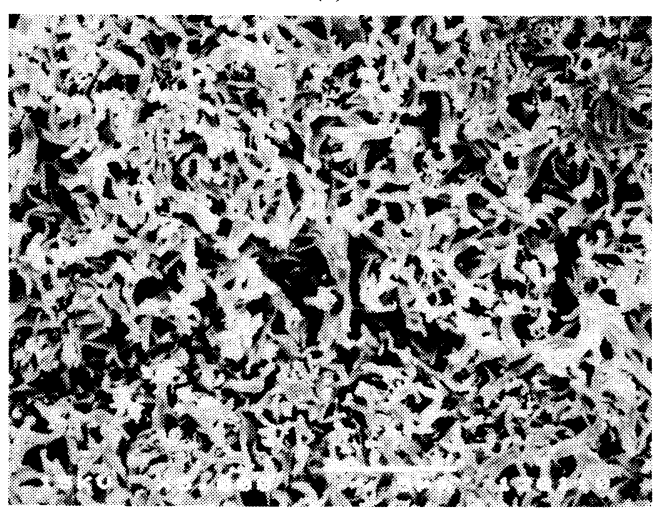

PBZT (10wt\%)-PI(BTDA/DAPBT) $5 \boldsymbol{\mu} \mathbf{m}$

(b)

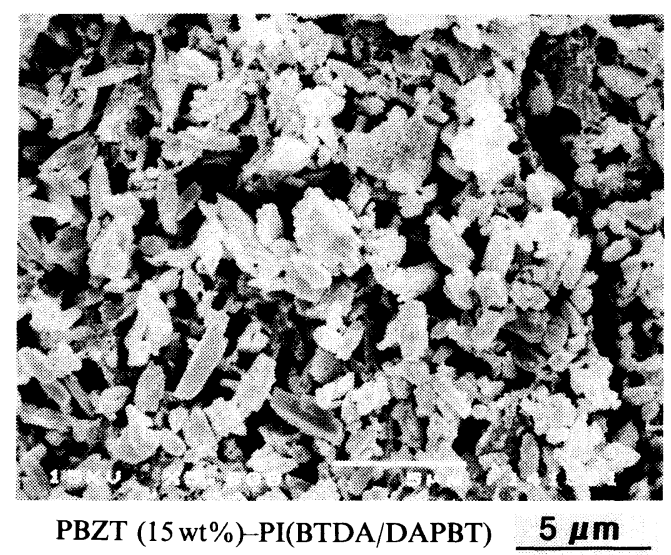

Figure 3. SEM photographs of the residue from the blends by the polymerization blending after treating with hydrazine: (a) the PBZT (10wt\%)-PI(BTDA/DAPBT) blend; (b) the PBZT (15wt\%)-PI(BTDA/DAPBT) blend.

also performed by the same treatment to contrast the preparation processes between the polymerization blending and the solution blending in morphology (Figure 4). Since the residue from the blend by the solution blending was also fibrous but coarse structure compared with the residue from the blend by the polymerization blending, the polymerization blending method is obviously superior to the solution blending giving excellent mechanical properties of the blend films.

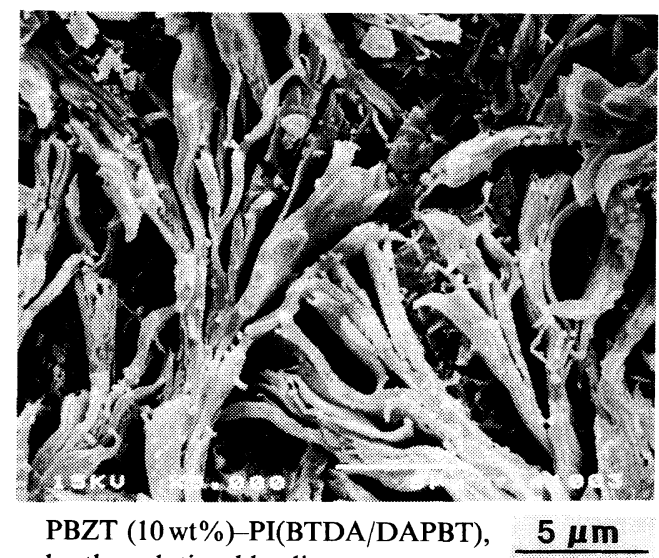

by the solution blending

Figure 4. SEM photographs of the residue from the PBZT (10wt \%)-PI(BTDA/DAPBT) blend by the solution blending after treating with hydrazine.

\section{Tensile Properties of Blend Films}

The initial modulus, tensile strength, and elongation at break of the blend films of the PBZT-PI(PMDA/APB) are shown in Figures 5,6 , and 7 , respectively. Since the modulus and strength increased with the PBZT content up to $5 \mathrm{wt} \%$ proportionally, the blend films were reinforced actually by the PBZT, however, both of them fell down rather drastically over the critical content of $5 \mathrm{wt} \%$. The morphology showed also obvious difference between them as the state of the dispersion, corresponding well to the mechanical properties.

Figures 8, 9, and 10 show the mechanical properties of the blend films of the PBZTPI(BTDA/DAPBT). The critical content for the mechanical properties of the films were $10 \mathrm{wt} \%$ of the PBZT and was higher than that of the films of the PBZT-PI(PMDA/APB) mentioned above. Common structure of the benzobisthiazole ring existing both in the PBZT and in PI(BTDA/DAPBT) improved compatibility between them to shift the critical concentration higher. The morphology of the film clearly showed fine fibrous structure of micro level even at $10 \mathrm{wt} \%$ of the PBZT, however, it changed coarser at $15 \mathrm{wt} \%$ of the PBZT. 
Preparation of Polybenzothiazole-Polyimide Blends

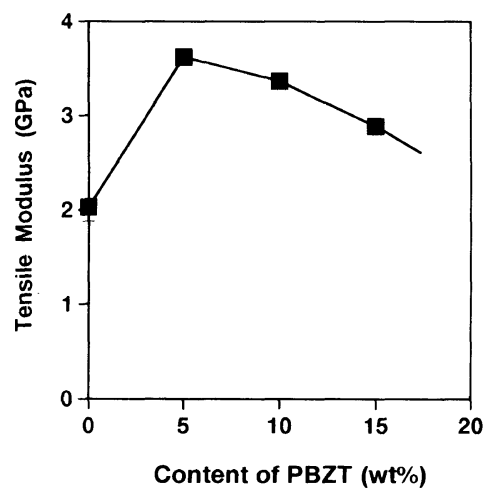

Figure 5. Tensile modulus of the blend films of the PBZT-PI(PMDA/APB).

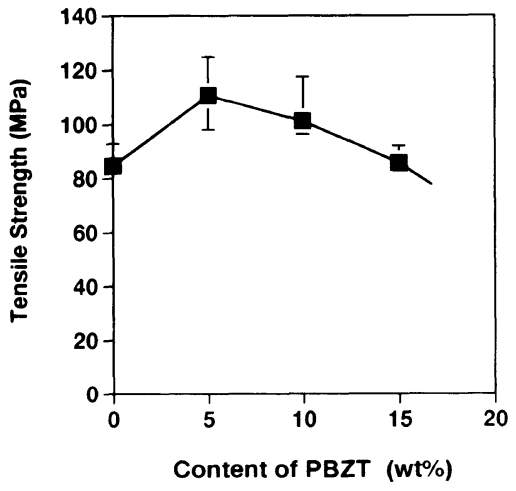

Figure 6. Tensile strength of the blend films of the PBZT-PI(PMDA/APB).

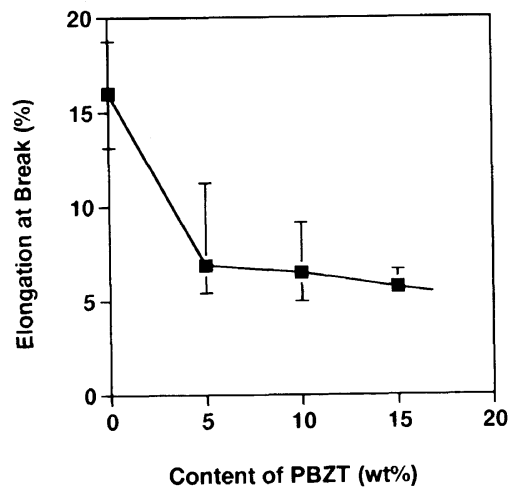

Figure 7. Elongation at break for the blend films of the PBZT-PI(PMDA/APB).

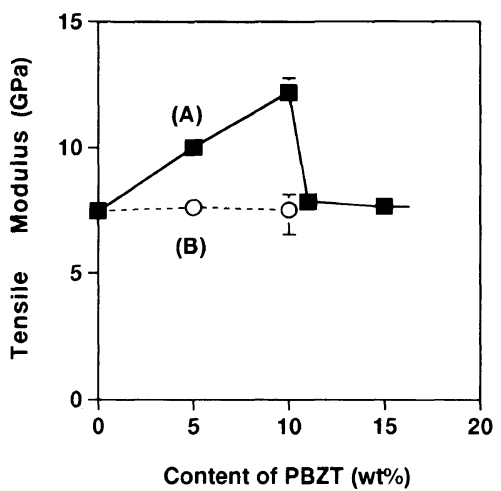

Figure 8. Tensile modulus of the blend films of the PBZT-PI(BTDA/DAPBT) by the method of (A) polymerization blending, and (B) solution blending.

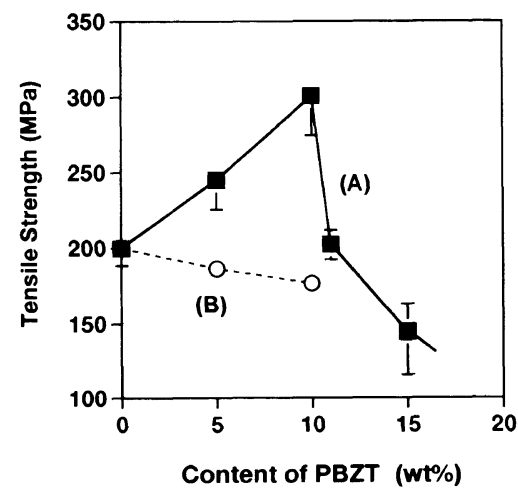

Figure 9. Tensile strength of the blend films of the PBZT-PI(BTDA/DAPBT) by the method of (A) polymerization blending, and (B) solution blending.

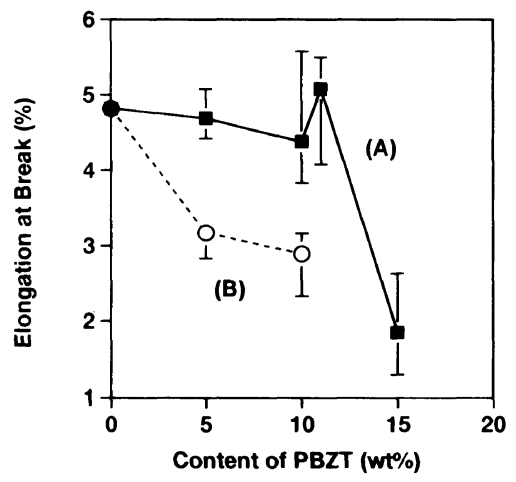

Figure 10. Elongation at break for the blend films of the PBZT-PI(BTDA/DAPBT) by (A) polymerization blending, and (B) solution blending. 
The films obtained by the solution blending, where the precursor polyamide solution and polyamic acid solution were prepared separately and then mixed together thoroughly, were also evaluated in order to compare with those by the polymerization blending. The mechanical properties of the films are also shown in Figures 8, 9, and 10. The modulus and strength of the solution blended films were on a level of those with the matrix, and hence no reinforcement effect was observed for the films obtained by the solution blending. The results suggested that the polymerization blending could achieve finer dispersion of the rigid-rod PBZT with preferable fibrous structure compared with the solution blending, thus, the former was an effective method to prepare micro-composites with excellent mechanical properties.

\section{Dynamic Mechanical Properties of Blend Films}

The dynamic mechanical properties of the blend films of the PBZT-PI(PMDA/APB) and the PBZT-PI(BTDA/DAPBT) by the polymerization blending were measured such as the storage modulus $\left(E^{\prime}\right)$ and the loss modulus $\left(E^{\prime \prime}\right)$. Figure 11 shows the temperature dependence of $E^{\prime}$ and $E^{\prime \prime}$ for the films of the PBZT-PI(PMDA/APB). The $E^{\prime}$ value of the blend film was almost the same level as that of the polyimide as matrix. The $E^{\prime \prime}$ curve of the matrix polyimide showed a peak for $T_{\mathrm{g}}$ at $320^{\circ} \mathrm{C}$, and the $T_{\mathrm{g}}$ did not shift significantly by the incorporation of the PBZT into the blend.

Figure 12 exhibits that the $E^{\prime}$ value for the blend film of the PBZT-PI(BTDA/DAPBT) by the polymerization blending was higher than that of matrix PI(BTDA/DAPBT) over the entire temperature range analyzed. The $E^{\prime \prime}$ curve of the matrix polyimide shows a peak for $T_{\mathrm{g}}$ at $320^{\circ} \mathrm{C}$, however, the corresponding $T_{\mathrm{g}}$ of the blend diminished appreciably and shifted to $330^{\circ} \mathrm{C}$. These results showed better compatibility in the binary blend of the PBZT and PI(BTDA/DAPBT), and corresponded well to the fact that the transparent film had

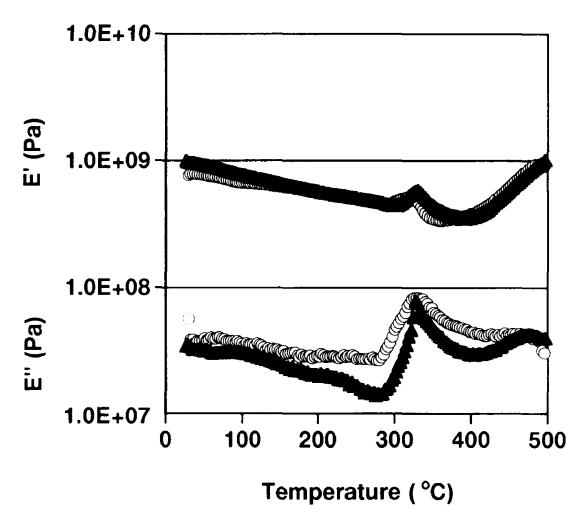

Figure 11. Dynamic mechanical properties of the films of (O) the PBZT (10wt \%)-PI(PMDA/APB), and (A) PI(PMDA/APB).

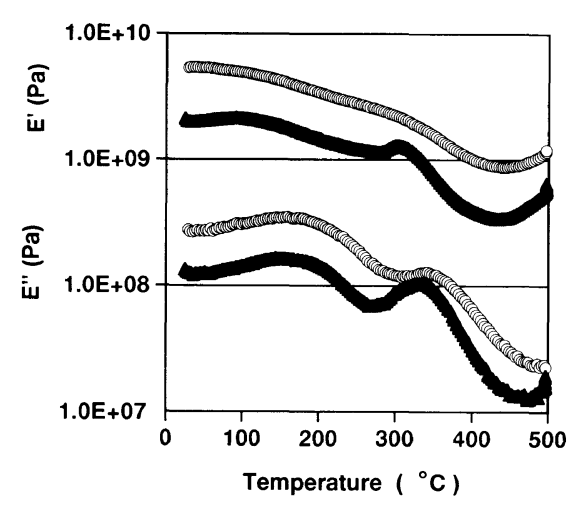

Figure 12. Dynamic mechanical properties of the films of $(O)$ the PBZT (10 wt \%)-PI(BTDA/DAPBT), and (A) PI(BTDA/DAPBT).

fine dispersion of the PBZT and hence excellent mechanical properties as shown above.

\section{CONCLUSIONS}

A new polymerization blending have been studied in order to prepare the micro-composites with fine dispersion of the PBZT as reinforcement in the polyimides as matrix and hence achieved excellent mechanical properties in the blend films. The films consisted of the PBZT and the polyimides were effectively reinforced by the rigid-rod PBZT to raise both of the tensile modulus and strength. The common structure of the benzobisthiazole ring 
existing in the PBZT and the matrix polyimide significantly shifted the critical concentration higher and led to better mechanical properties of the blend films than those without the common structure. The observation of the morphology by the SEM showed that the state of the dispersion was improved to give fine fibrous structure, suggesting enhanced compatibility between the PBZT and the polyimide. The morphology of the PBZT was apparently affected by the structure of matrix polymer, the content of the PBZT, and the process of blending, corresponding well to mechanical properties of the blends. The films obtained by the simple solution blending method showed no reinforcement effect of the PBZT actually. Thus, the method of the polymerization blending is a promising way to obtain microcomposite materials.

\section{REFERENCES}

1. Y. Imai, I. Taoka, K. Uno, and Y. Iwakura, Makromol. Chem., 83, 167 (1965).

2. P. M. Hergenrother, W. Wrasidlo, and H. H. Levine, J. Polym. Sci., A, 3, 1665 (1965).

3. J. F. Wolfe, B. H. Loo, and F. E. Arnold, Macromolecules, 14, 915 (1981).

4. S. R. Allen, A. G. Filippov, R. J. Farris, and E. L. Thomas, J. Appl. Polym. Sci., 26, 291 (1981).

5. S. R. Allen, A. G. Filippov, R. J. Farris, E. L. Thomas, C. P. Wong, G. C. Berry, and E. C.
Chenevey, Macromolecules, 14, 1135 (1981).

6. L. Feldman, R. J. Farris, and E. L. Thomas, J. Mater. Sci., 20, 2719 (1985).

7. S. R. Allen, R. J. Farris, and E. L. Thomas, J. Mater. Sci., 20, 2727 (1985).

8. S. R. Allen, R. J. Farris, and E. L. Thomas, J. Mater. Sci., 20, 4583 (1985).

9. T. Hattori, H. Akita, M. Kakimoto, and Y. Imai, $J$. Polym. Sci., A, Polym. Chem., Ed., 30, 197 (1992).

10. T. Hattori, H. Akita, M. Kakimoto, and Y. Imai, Macromolecules, 25, 3351 (1992).

11. T. Hattori, K. Kagawa, M. Kakimoto, and Y. Imai, Macromolecules, 26, 4089 (1993).

12. T. Hattori, K. Kagawa, M. Kakimoto, and Y. Imai, Polym. J., 26, 930 (1994).

13. M. Takayanagi, T. Ogata, M. Morikawa, and T. Kai, J. Macromol. Sci., Phys., B17, 591 (1980).

14. W. F. Hwang, D. R. Wiff, C. Verschoore, G. E. Price, T. E. Helminiak, and W. W. Adams, Polym. Eng. Sci., 23, 784 (1983).

15. W. F. Hwang, D. R. Wiff, C. L. Benner, and T. E. Helminiak, J. Macromol. Sci. Phys., B22, 231 (1983).

16. R. Yokota, R. Horiuchi, M. Kochi, H. Soma, and I. Mita, J. Polym. Sci., C, 26, 215 (1988).

17. K. Yamada, T. Mitsutake, M. Takayanagi, and T. Kajiyama, J. Macromol. Sci., Chem., A26, 891 (1989).

18. H. Hayashi, M. Kakimoto, and Y. Imai, Kobunshi Ronbunshu, 50, 605 (1993).

19. H. Hayashi, S. Nakata, M. Kakimoto, and Y. Imai, J. Appl. Polym. Sci., 49, 1241 (1993).

20. N. Ogata, K. Sanui, and H. Itaya, Polym. J., 22, 85 (1990).

21. K. Sanui, N. Ogata, K. Kamitani, and M. Watanabe, J. Polym. Sci., Polym. Chem. Ed., 31, 597 (1993).

22. T. Tayama, M. Kimura, and S. Mukai, Mitsubishi Kasei R\& D Review, 4, 98 (1990). 